\title{
Digestion rate of dietary starch affects systemic circulation of amino acids in weaned pigs
}

\author{
Fugui Yin ${ }^{1}$, Zhenzhen Zhang ${ }^{1,2}$, Ju Huang ${ }^{1}$ and Yulong Yin ${ }^{1,2 *}$ \\ ${ }^{1}$ Key Laboratory for Agro-ecological Processes in Subtropical Region, Institute of Subtropical Agriculture, \\ CAS, Hunan 410125, China \\ ${ }^{2}$ National Key Laboratory of Food Science and Technology, College of Life Science, Nanchang University, \\ Nanchang, Jiangxi 330047, China
}

(Received 24 April 2009 - Revised 4 November 2009 - Accepted 9 November 2009 - First published online 27 January 2010)

The present study was conducted to evaluate the in vitro and in vivo digestibility of dietary starch and its digestive behaviour on the systemic circulating amino acids (AA) in weaned pigs. Eighteen weanling pigs surgically fitted with a catheter in the jugular vein were randomly assigned to three dietary treatment groups. Sticky rice starch (SRS) was hydrolysed more quickly in vitro $(P<0.05)$ than maize starch $($ MS) and resistant starch (RS), and was almost completely hydrolysed within $4 \mathrm{~h}$. The in vivo digestibility of dietary starch in different segments of the small intestine was significantly different. SRS was digested $(81.9 \% ; P<0.05)$ in the anterior jejunum, but not more than half of the MS and RS was digested in the same segment of the small intestine. The digestibilities of isoleucine, leucine, methionine, phenylalanine, threonine, tryptophan, valine, alanine, aspartate and serine in the SRS group were higher than in the MS group $(P<0.05)$, and all nutritionally indispensable and dispensable AA in the SRS group were higher when compared with those in the RS group $(P<0 \cdot 05)$. The serum concentrations of nutritionally indispensable AA, proline and serine in the three groups were increased to a peak point within $1.5 \mathrm{~h}$ postprandially then decreased gradually; however, the time that serum concentrations of alanine, aspartate, glutamate and glycine in each group increased to a peak point was different. The concentrations of nutritionally indispensable AA, including arginine, cystine, histidine, isoleucine, leucine, methionine, phenylalanine, threonine, tryptophan, tyrosine and valine at 09.30 hours and arginine, cystine, histidine, isoleucine, methionine, phenylalanine, threonine, tryptophan, tyrosine and valine at 13.30 hours in the SRS group were higher than in the MS group $(P<0.05)$; all nutritionally indispensable AA in the SRS group were higher than in the RS group at 09.30 and 13.30 hours $(P<0.05)$, respectively. We conclude that dietary starches digested rapidly in vitro have higher digestibility in the anterior small intestine of pigs. Diets containing rapidly digestible starch ameliorate the digestive and absorptive function and regulate AA metabolism to beneficially increase the entry of dietary AA into the systemic circulation in pigs.

Digestion rate: Starch: Amino acids: Pigs

Starch, acting as the major energy-yielding component of the daily diet, is the main carbohydrate in mammal (including human) nutrition ${ }^{(1)}$. The glucose release as a source of energy for the body and the timeline of digestion are the major physiological properties of $\operatorname{starch}^{(2)}$. Previous research has found that the digestibility of starch in the small intestine of mammals can be modified from a rapid digestion to indigestibility ${ }^{(3)}$; thus for nutritional purposes, starch has been divided into rapidly digestible starch, slowly digestible starch and resistant starch (RS) to specify its nutritional quality related to physiological response and health effects ${ }^{(4)}$. Rapidly digestible starch leads to a rapid increase in blood glucose and insulin levels ${ }^{(5)}$, whereas slowly digestible starch has moderate glycaemic and insulinaemic responses. The same results were observed in pigs by Van der Meulen et al. ${ }^{(6)}$ and Noah et al. ${ }^{(7)}$. However, the latest research from Liu et al. ${ }^{(8)}$ was rather different from the Van der Meulen et al. ${ }^{(6)}$ and Noah et al. ${ }^{(7)}$ research. A worthwhile finding that postprandial blood glucose and insulin levels were higher in pigs fed diets containing rapidly digestible starch than those fed diets containing maize starch (MS) and RS within $4 \mathrm{~h}$ was found when our team studied the papers of Van der Meulen et al. ${ }^{(6)}$, Noah et al. ${ }^{(7)}$ and Liu et al. ${ }^{(8)}$. Besides, the degree of digestion and the rate of starch digestion in different segments of the small intestine in pigs are still unclear. Furthermore, there is some debate as to whether slowly digested starch or rapidly digested starch will lead to higher postprandial systemic circulating amino acid (AA) levels. We hypothesised that if pigs consumed their meals every $4 \mathrm{~h}$, and six times within $24 \mathrm{~h}$, higher blood metabolite levels would be obtained, as well as better growth performance. The objectives of the present study were to determine the digestibility of starch by in vitro and in vivo methods, and to evaluate the postprandial systemic circulating levels of blood metabolites (mainly AA) in pigs under a 'six time intake per d' feeding procedure.

Abbreviations: AA, amino acid; MS, maize starch; mTOR, mammalian target of rapamycin; RS, resistant starch; SRS, sticky rice starch.

* Corresponding author: Dr Yulong Yin, fax +86 7318461 2685, email yinyulong@isa.ac.cn 


\section{Materials and methods \\ Preparation of starches}

MS and sticky rice starch (SRS) were commercially available from Changsha food market (Changsha, Hunan, China). RS was purchased from National Starch Specialties (Shanghai) Limited (Shanghai, Jiangsu, China).

\section{Animals, experimental design and diets}

The present study involved an in vitro digestibility trial (experiment 1) and an animal experiment (experiment 2). The protocol for the animal experiment was approved by the Animal Care and Use Committee of the Institute of Subtropical Agriculture, The Chinese Academy of Sciences.

Experiment 1: in vitro digestibility trial. The in vitro digestibility of dietary starch was determined based on the previous method described by Englyst et al. ${ }^{(3)}$ and Hung \& Morita $^{(9)}$ with minor modification. Briefly, $100 \mathrm{mg}$ sample was incubated with porcine pancreatic $\alpha$-amylase (no. 7545; Sigma-Aldrich, St Louis, MO, USA) and amyloglucosidase (no. 9913, Sigma-Aldrich) in $4 \mathrm{ml}$ of a $0.1 \mathrm{M}$-sodium maleate buffer ( $\mathrm{pH} 6.0)$ in a shaking water-bath $(200$ strokes/min) at $37^{\circ} \mathrm{C}$ for 0.5 to about $6 \mathrm{~h}$. After incubation, ethanol $(95 \%)$ was added and the sample was then centrifuged at $3000 \mathrm{rpm}$ for $10 \mathrm{~min}$. The glucose content of the supernatant fraction was measured using a CX4PRO Select Biochemistry Analyser (Beckman Coulter Inc., Fullerton, CA, USA). The digested starch content was thus determined from the glucose content in the supernatant fraction. Digestibility is expressed as the ratio of the content of digested starch at each incubation time point to the content of the total starch of the sample.

Experiment 2: animal experiment. Eighteen barrows, weaned at age $21 \mathrm{~d}$ with an average initial body weight of 7.04 (SD 0.52$) \mathrm{kg}$, were allocated on the basis of weight and litter of origin to three dietary treatments in a randomised complete block design. Each pig was surgically fitted with a catheter in the jugular vein according to the procedures described by Huang et al. ${ }^{(10)}$ and Li et al. ${ }^{(11)}$. The preparation of catheters and detailed description of pre- and post-operative care were previously described by $\mathrm{Li}$ et al. ${ }^{(11)}$. The pigs were returned to the metabolic crates immediately after surgery. Each crate was equipped with a suspended water line fitted with a low-pressure nipple and wire flooring. During a $3 \mathrm{~d}$ recovery period, an antibiotic (penicillin) was administered intravenously to the animal. The catheters were checked for potency by flushing and filling with sodium heparin solution daily. The skin around the catheter was cleaned with lukewarm water daily, dried, and a skin-protecting paste was applied (Stomahesive Paste; ConvaTec, Princeton, NJ, USA). The pigs were trained to adapt to a new feeding procedure. Briefly, all pigs were fed six times daily $(04.00,08.00,12.00,16.00,20.00$ and 24.00 hours) and trained to consume their meals within $10 \mathrm{~min}$. Water was freely available. The temperature was kept at $26 \pm 2{ }^{\circ} \mathrm{C}$, and relative humidity was maintained from 60 to $75 \%$. Following recovery, the pigs were fed the experimental diets.

Venous blood samples were taken from each pig via a catheter into $5 \mathrm{ml}$ heparin-free vacutainer tubes (Becton Dickinson Vacutainer Systems, Franklin Lakes, NJ, USA) hourly from 08.30 to 15.30 hours on day 7. All samples were centrifuged at $3000 \mathrm{rpm}$ (Heraeus Biofuge 22R
Centrifuge; Hanau, Germany) for $10 \mathrm{~min}$ at $4^{\circ} \mathrm{C}$, and serum samples were immediately separated and placed in test-tubes and stored at $-20^{\circ} \mathrm{C}$ for later analysis. The pigs were still fed six times daily according to the feeding procedure during the sample collection period. On day 8, all pigs were fed at 08.00 hours and then euthanised at 11.00 hours. Digesta samples were collected from the anterior jejunum, posterior jeunum, anterior ileum and posterior ileum of each pig and stored at $-20^{\circ} \mathrm{C}$. When the sampling was completed, all digesta samples were freeze-dried and ground through a $0 \cdot 10 \mathrm{~mm}$ mesh screen for chemical analysis.

Dietary crude protein, nutritional indispensable AA, vitamins and minerals were supplemented to meet or exceed the National Research Council's nutritional requirements for swine $^{(12)}$ with body weight of $5-10 \mathrm{~kg}$. Ingredients and AA composition of the diets are summarised in Tables 1 and 2, respectively.

\section{Chemical analysis}

DM and crude protein contents were analysed according to AOAC procedures ${ }^{(13)}$. Total starch content was measured by American Association of Cereal Chemists (AACC) method $76 \cdot 13^{(14)}$. Serum AA concentrations were determined using a Hitachi L-8800 Amino Acid Analyser (Tokyo, Japan), as previously described by Yao et al. ${ }^{(15)}$. AA analyses of the diet and posterior ileum digesta were previously described by Yin et al. ${ }^{(16)}$. Titanium oxide concentration was determined according to the method described by Yin et al. ${ }^{(17)}$.

Table 1. Ingredients and chemical composition of the experimental diets

\begin{tabular}{lrrr}
\hline & \multicolumn{3}{c}{ Treatment } \\
\cline { 2 - 4 } & MS group & SRS group & RS group \\
\hline Ingredients (\%) & & & \\
SRS & 0.00 & 70.92 & 0.00 \\
MS & 70.92 & 0.00 & 0.00 \\
RS & 0.00 & 0.00 & 70.92 \\
Zein (crude protein 90\%) & 18.00 & 18.00 & 18.00 \\
Soyabean oil & 3.00 & 3.00 & 3.00 \\
L-Lysine-HCl & 1.20 & 1.20 & 1.20 \\
DL-Methionine & 0.06 & 0.06 & 0.06 \\
L-Tryptophan & 0.20 & 0.20 & 0.20 \\
Ca(H HO $\left._{4}\right)_{2}$ & 0.60 & 0.60 & 0.60 \\
CaCO & 0.74 & 0.74 & 0.74 \\
Acidifier & 1.00 & 1.00 & 1.00 \\
Flavour & 0.10 & 0.10 & 0.10 \\
Choline chloride (50\%) & 0.08 & 0.08 & 0.08 \\
Premixt & 4.00 & 4.00 & 4.00 \\
Titanium oxide & 0.10 & 0.10 & 0.10 \\
Analysed composition (\%) & & & \\
DM & 94.79 & 95.53 & 94.60 \\
Total starch & 68.92 & 69.31 & 68.34 \\
Crude protein & 17.48 & 17.62 & 17.34 \\
Ca & 0.92 & 0.90 & 0.93 \\
P & 0.54 & 0.52 & 0.53 \\
& & &
\end{tabular}

MS, maize starch; SRS, sticky rice starch; RS, resistant starch.

* Provided by Guangzhou Tianke Industry Co. (Guangzhou, Guangdong, China).

†Supplied (per kg diet): vitamin A, $6 \mathrm{mg}$; vitamin $D_{3}, 8 \mathrm{mg}$; vitamin $E, 30 \mathrm{mg}$; vitamin K, $3 \mathrm{mg}$; vitamin $\mathrm{B}_{2}, 27 \mathrm{mg}$; vitamin $\mathrm{B}_{6}, 2 \mathrm{mg}$; vitamin $\mathrm{B}_{12}, 30 \mu \mathrm{g}$; biotin, $80 \mu \mathrm{g}$; folic acid, $8 \mathrm{mg}$; nicotinic acid, $24 \mathrm{mg}$, Na (NaCl), $3 \mathrm{~g}, \mathrm{Zn}\left(\mathrm{ZnSO}_{4}\right), 165 \mathrm{mg}$; $\mathrm{Fe}\left(\mathrm{FeSO}_{4}\right), 165 \mathrm{mg} ; \mathrm{Mn}\left(\mathrm{MnSO}_{4}\right), 33 \mathrm{mg} ; \mathrm{Cu}\left(\mathrm{CuSO}_{4}\right), 165 \mathrm{mg}$, iodine $\left(\mathrm{Cal}_{2}\right)$, $297 \mu \mathrm{g} ; \mathrm{Se}\left(\mathrm{Na}_{2} \mathrm{SeO}_{3}\right), 297 \mu \mathrm{g}$. 
Table 2. Analysed amino acid composition of the experimental diets (\%)

\begin{tabular}{lccc}
\hline & \multicolumn{3}{c}{ Treatment } \\
\cline { 2 - 4 } & MS group & SRS group & RS group \\
\hline Nutritionally indispensable amino acids & & \\
Arginine & 0.15 & 0.15 & 0.16 \\
Cystine & 0.16 & 0.16 & 0.15 \\
Histidine & 0.18 & 0.16 & 0.15 \\
Isoleucine & 0.54 & 0.57 & 0.54 \\
Leucine & 2.51 & 2.45 & 2.50 \\
Lysine & 1.51 & 1.48 & 1.52 \\
Methionine & 0.29 & 0.26 & 0.28 \\
Phenylalanine & 1.03 & 1.05 & 1.03 \\
Threonine & 0.35 & 0.41 & 0.36 \\
Tryptophan & 0.84 & 0.86 & 0.83 \\
Tyrosine & 0.53 & 0.56 & 0.49 \\
Valine & 0.56 & 0.58 & 0.57 \\
Nutritionally dispensable amino acids & & \\
Alanine & 1.16 & 1.19 & 1.17 \\
Aspartate & 0.64 & 0.59 & 0.65 \\
Glutamate & 3.28 & 3.26 & 3.28 \\
Glycine & 0.12 & 0.11 & 0.13 \\
Proline & 2.36 & 2.38 & 2.30 \\
Serine & 0.61 & 0.68 & 0.61 \\
\hline
\end{tabular}

MS, maize starch; SRS, sticky rice starch; RS, resistant starch.

The apparent digestibility of dietary starches in different fragments of the small intestine and the apparent digestibility of AA in the digesta of the posterior ileum were calculated using the following equations, as described by Fan et al. ${ }^{(18)}$ with minor modification:

$$
\mathrm{S}_{\mathrm{AD}}=\left(1-\mathrm{S}_{\mathrm{d}} \times \mathrm{TiO}_{2 \mathrm{f}} / \mathrm{S}_{\mathrm{f}} \times \mathrm{TiO}_{2 \mathrm{~d}}\right) \times 100 \%,
$$

where $\mathrm{S}_{\mathrm{AD}}$ is the apparent small intestine digestibility of starch or AA, $\mathrm{S}_{\mathrm{f}}$ is the total starch or AA concentration in the diet, $S_{d}$ is the total starch or AA concentration in the small intestine digesta, $\mathrm{TiO}_{2 \mathrm{f}}$ is the titanium oxide concentration in the diet and $\mathrm{TiO}_{2 \mathrm{~d}}$ is the titanium oxide concentration in the digesta.

\section{Statistical analysis}

All physico-chemical analyses were performed at least in duplicate. The data on in vitro and in vivo digestibility of starches and apparent posterior ileum digestibility of AA

Table 3. In vitro digestibility of dietary starch at different incubation times (\%) ( $n 6$ per group)

(Mean values and pooled standard errors of the mean)

\begin{tabular}{|c|c|c|c|c|}
\hline \multirow[b]{2}{*}{ IT (h) } & \multicolumn{3}{|c|}{ Treatment } & \multirow[b]{2}{*}{ Pooled SEM } \\
\hline & MS & SRS & RS & \\
\hline 0.5 & $26.53^{b}$ & $40 \cdot 61^{a}$ & $12 \cdot 00^{c}$ & $1 \cdot 17$ \\
\hline 1 & $43.91^{b}$ & $57 \cdot 11^{a}$ & $19 \cdot 53^{c}$ & 1.59 \\
\hline 2 & $74 \cdot 30^{\mathrm{b}}$ & $91 \cdot 62^{a}$ & $26 \cdot 97^{c}$ & $2 \cdot 88$ \\
\hline 3 & $87 \cdot 28^{b}$ & $95 \cdot 94^{a}$ & $39.75^{c}$ & $2 \cdot 54$ \\
\hline 4 & $90 \cdot 95^{\mathrm{b}}$ & $98 \cdot 77^{\mathrm{a}}$ & $45 \cdot 83^{c}$ & $2 \cdot 31$ \\
\hline 5 & $92 \cdot 48^{\mathrm{b}}$ & $99 \cdot 02^{\mathrm{a}}$ & $51 \cdot 73^{c}$ & $2 \cdot 10$ \\
\hline 6 & $95 \cdot 76^{b}$ & $99 \cdot 81^{a}$ & $53 \cdot 23^{c}$ & $2 \cdot 11$ \\
\hline
\end{tabular}

IT, incubation time; MS, maize starch; SRS, sticky rice starch, RS, resistant starch. ${ }^{a, b, c}$ Mean values within a row with unlike superscript letters were significantly different $(P<0.05)$. were analysed by one-way ANOVA using the general linear model (GLM) procedure of SAS for a randomised complete block design (SAS Institute, Inc., Cary, NC, USA). The data on serum-free AA concentrations were analysed as a splitplot design for repeated measures using the GLM procedure of SAS. The statistical model included the effect of treatment as the main plot (tested by the animal within treatment variance) and the effects of time and the treatment $\times$ time interaction as the subplots. Comparisons among treatments within sampling time were made when a significant $F$ test $(P<0.05)$ for the treatment $\times$ time interaction was observed. Duncan's multiple-comparison test was used to determine differences among the means of treatment groups. $P<0.05$ was taken to indicate statistical significance.

\section{Results}

In vitro digestibility of dietary starch (experiment 1)

The digestibility of the three dietary starches was increased when the incubation time was extended (Table 3). SRS was hydrolysed more quickly $(P<0.05)$ than MS and RS, and was almost completely hydrolysed within $4 \mathrm{~h}$. The hydrolysis rate of MS remained at a slow and steady pace, and $95.76 \%$ was hydrolysed within $6 \mathrm{~h}$. The hydrolysis rate of RS was even slower $(P<0.05)$ than that of MS, and only $52.66 \%$ was hydrolysed when the incubation time was extended to $6 \mathrm{~h}$.

\section{Animal experiment (experiment 2)}

In experiment 2, pigs were healthy and consumed their meals. In this experiment, the pigs in the SRS group consumed their meals within $6 \mathrm{~min}$, which was faster than the pigs in the other two groups. Although pigs in the MS and RS groups consumed their diets slowly, they still completed their feed intake within $10 \mathrm{~min}$. All pigs were euthanised on day 8 . Examination of the catheter site revealed no abnormalities.

\section{In vivo digestibility of dietary starches}

The degree of hydrolysis of SRS in different segments of the small intestine was higher $(P<0.05)$ than that of MS, and that of MS was also higher $(P<0 \cdot 05)$ than of RS in turn (Table 4). Notably, compared with MS and RS, SRS was easily $(P<0.05)$ hydrolysed, $81.90 \%$ of which was hydrolysed in

Table 4. Digestibility of dietary starches in different segments of the small intestine in piglets (\%) (n 6 per group)

(Mean values and pooled standard errors of the mean)

\begin{tabular}{lcccc}
\hline \multirow{2}{*}{ Small intestine segments } & \multicolumn{3}{c}{ Treatment } & \\
\cline { 2 - 4 } & MS & SRS & RS & Pooled SEM \\
\hline Anterior jejunum & $47.17^{\mathrm{b}}$ & $81.90^{\mathrm{a}}$ & $30 \cdot 14^{\mathrm{c}}$ & 2.69 \\
Posterior jejunum & $74.21^{\mathrm{b}}$ & $91.98^{\mathrm{a}}$ & $46 \cdot 30^{\mathrm{c}}$ & 2.67 \\
Anterior ileum & $83.81^{\mathrm{b}}$ & $96 \cdot 04^{\mathrm{a}}$ & $53 \cdot 74^{\mathrm{c}}$ & 2.19 \\
Posterior ileum & $93.08^{\mathrm{b}}$ & $99.81^{\mathrm{a}}$ & $67.48^{\mathrm{c}}$ & 1.64 \\
\hline
\end{tabular}

MS, maize starch; SRS, sticky rice starch, RS, resistant starch.

${ }^{a, b, c}$ Mean values within a row with unlike superscript letters were significantly different $(P<0.05)$. 
the anterior jejunum, but not more than half of MS and RS was hydrolysed in the same site of the jejunum. SRS was completely digested in the posterior ileum, and $93.08 \%$ of MS was also hydrolysed in the same site of the ileum. RS was difficult to hydrolyse in the small intestine; only $67.48 \%$ of RS was hydrolysed in the posterior ileum.

\section{Apparent posterior ileum digestibility of amino acids}

The digestibility of isoleucine, leucine, methionine, phenylalanine, threonine, tryptophan, valine, alanine, aspartate and serine in the SRS group was higher $(P<0 \cdot 05)$ than in the MS group (Table 5). All nutritionally indispensable and dispensable AA in the SRS group were higher when compared with those in the RS group $(P<0 \cdot 05)$. The digestibility of lysine, phenylalanine, tyrosine, valine, glutamate and proline in the MS group was higher $(P<0 \cdot 05)$ than in the RS group.

\section{Serum circulating amino acids}

The postprandial serum concentration of AA at different time points and variation in postprandial systemic circulating lysine, methionine and tryptophan are summarised in Tables 6 and 7 and Figs. 1-3, respectively. All AA were affected $(P<0.05)$ by treatment as well as time and treatment $\times$ time interaction. Consequently, comparisons of the means among treatments within sampling time were made. At 08.30 hours, concentrations of arginine, cystine, leucine, lysine, threonine, tryptophan, tyrosine, alanine, glycine, proline and serine in the SRS group and leucine and proline in the MS group were higher $(P<0.05)$ than in the RS group. Threonine and alanine in the SRS group were higher $(P<0.05)$ than in the MS group. At 09.30 hours, concentrations of all nutritionally

Table 5. Apparent posterior ileum digestibility of amino acids (\%) ( $n 6$ per group)

(Mean values and pooled standard errors of the mean)

\begin{tabular}{|c|c|c|c|c|}
\hline & \multicolumn{3}{|c|}{ Treatment } & \multirow[b]{2}{*}{ Pooled SEN } \\
\hline & MS & SRS & RS & \\
\hline \multicolumn{5}{|c|}{ Nutritionally indispensable amino acids } \\
\hline Arginine & $80 \cdot 78^{a, b}$ & $85 \cdot 17^{\mathrm{a}}$ & $74.33^{\mathrm{b}}$ & 1.68 \\
\hline Cystine & $72 \cdot 35^{\mathrm{a}, \mathrm{b}}$ & $78 \cdot 33^{\mathrm{a}}$ & $65 \cdot 43^{\mathrm{b}}$ & 1.50 \\
\hline Histidine & $79 \cdot 58^{a, b}$ & $83.87^{a}$ & $74.87^{\mathrm{b}}$ & 0.97 \\
\hline Isoleucine & $72 \cdot 00^{\mathrm{b}}$ & $77 \cdot 45^{\mathrm{a}}$ & $68 \cdot 25^{\mathrm{b}}$ & 0.93 \\
\hline $\begin{array}{l}\text { Leucine } \\
\text { Le }\end{array}$ & $77 \cdot 28^{\mathrm{b}}$ & $86 \cdot 42^{\mathrm{a}}$ & $70 \cdot 47^{\mathrm{b}}$ & 0.79 \\
\hline Lysine & $80 \cdot 48^{\mathrm{a}}$ & $85.40^{\mathrm{a}}$ & $72 \cdot 12^{\mathrm{b}}$ & 1.22 \\
\hline Methionine & $73 \cdot 65^{\mathrm{b}}$ & $78.57^{\mathrm{a}}$ & $70 \cdot 03^{\mathrm{b}}$ & 1.04 \\
\hline Phenylalanine & $75 \cdot 07^{\mathrm{b}}$ & $82.53^{a}$ & $69.63^{\mathrm{c}}$ & 0.77 \\
\hline Threonine & $77 \cdot 80^{\mathrm{b}}$ & $82 \cdot 70^{\mathrm{a}}$ & $73.37^{\mathrm{b}}$ & $1 \cdot 12$ \\
\hline Tryptophan & $75 \cdot 33^{\mathrm{b}}$ & $84 \cdot 15^{\mathrm{a}}$ & $72 \cdot 48^{\mathrm{b}}$ & 0.69 \\
\hline Tyrosine & $76 \cdot 83^{a}$ & $78 \cdot 28^{a}$ & $70 \cdot 77^{\mathrm{b}}$ & 0.74 \\
\hline Valine & $76 \cdot 03^{\mathrm{b}}$ & $82.90^{\mathrm{a}}$ & $68 \cdot 65^{c}$ & 0.83 \\
\hline \multicolumn{5}{|c|}{ Nutritionally dispensable amino acids } \\
\hline Alanine & $73 \cdot 27^{\mathrm{b}}$ & $84 \cdot 15^{\mathrm{a}}$ & $71.57^{\mathrm{b}}$ & 0.75 \\
\hline Aspartate & $73.43^{\mathrm{b}}$ & $78 \cdot 33^{a}$ & $71 \cdot 18^{\mathrm{b}}$ & 0.97 \\
\hline Glutamate & $76 \cdot 77^{\mathrm{a}}$ & $75 \cdot 28^{a}$ & $70 \cdot 10^{\mathrm{b}}$ & 0.70 \\
\hline Glycine & $77 \cdot 03^{\mathrm{a}, \mathrm{b}}$ & $83 \cdot 10^{a}$ & $72 \cdot 73^{\mathrm{b}}$ & 1.50 \\
\hline Proline & $82 \cdot 30^{a}$ & $87.51^{a}$ & $73.13^{b}$ & 0.81 \\
\hline Serine & $72.75^{\mathrm{b}}$ & $78.70^{\mathrm{a}}$ & $70.27^{\mathrm{b}}$ & 0.88 \\
\hline
\end{tabular}

MS, maize starch; SRS, sticky rice starch, RS, resistant starch.

${ }^{a, b}, c$ Mean values within a row with unlike superscript letters were significantly different $(P<0.05)$. indispensable AA, alanine, glycine and proline in the SRS group, as well as lysine and proline in the MS group, were higher $(P<0.05)$ but concentrations of glutamate in the SRS group and threonine and valine in the MS group were lower $(P<0.05)$ than in the RS group. Concentrations of most nutritionally indispensable AA, except for lysine, and alanine and proline in the SRS group were higher $(P<0.05)$ than in the MS group. At 10.30 hours, concentrations of arginine, isoleucine, leucine, lysine, methionine, phenylalanine, threonine, tryptophan, tyrosine, valine, alanine, glutamate, glycine and proline in the SRS group were higher $(P<0.05)$ than in the RS group, and arginine and proline in the MS group likewise. Concentrations of arginine, lysine, methionine, phenylalanine, tyrosine, valine and proline in the SRS group were higher $(P<0.05)$ than in the MS group. At 11.30 hours, concentrations of lysine, methionine, threonine, tryptophan, tyrosine, valine, alanine, aspartate, glutamate, glycine in the SRS group and lysine, threonine, alanine and glycine in the MS group were higher $(P<0.05)$ but glutamate in the MS group was lower $(P<0 \cdot 05)$ compared with the RS group. Concentrations of isoleucine, methionine, valine, aspartate and glutamate in the SRS group were higher $(P<0.05)$ than in the MS group. During the second feeding cycle, from 12.30 to 15.30 hours, the variation in postprandial systemic circulating AA was the same as that observed during the first feeding cycle, from 08.30 to 11.30 hours.

\section{Discussion}

Starch was once presumed to be almost completely digested in mammals at all ages; however, recent research has found that the digestibility of starches from different sources in the mammal small intestine are different. Starches with a high amount of amylose are hard to hydrolyse, whereas fully gelatinised amylopectin is easily digested, which serves as a source of rapidly digestible $\operatorname{starch}^{(19)}$. Thus, the ratio of amylose:amylopectin affects starch digestibility and its physiological response. In the present study, MS contains $23.6 \%$ of amylose and $76.4 \%$ of amylopectin, SRS contains $100 \%$ of amylopectin and RS contains $96.5 \%$ amylose as determined in our preliminary experiment. The present results confirmed that amylopectin is more easily digested than amylose in an in vitro digestibility model, as well as in the pig small intestine again. In vitro digestibility of SRS is significantly higher than that of MS and RS at different time points within $6 \mathrm{~h}$ incubation. Furthermore, $81.90 \%$ of SRS was digested in the anterior jejunum, while only $47.17 \%$ of MS and $30.14 \%$ of RS were digested in the same segments of the small intestine. As the digesta flowed into different segments of the small intestine, the digestibilities of MS, SRS and RS were increased but the increasing ranges of SRS were lower than of MS and RS. Human clinical data showed that RS and slowly digestible starch offered the advantage of a slow increase in postprandial blood glucose levels, and sustained blood glucose levels over time compared with rapidly digestible starch, such as SRS, with its fast and high peak and fast decline ${ }^{(20-22)}$. Similar results were also observed in pigs by Van der Meulen et al. ${ }^{(6)}$ and Noah et al. ${ }^{(7)}$; thus the present results of dietary starch digestibility in different segments of the small intestine can explain why slowly digestible starch, rapidly digestible 
Table 6. Serum amino acid concentrations after first feeding ( $\mathrm{mmol} / \mathrm{l})$ ( $n 6$ per group)

(Mean values and pooled standard errors of the mean)

\begin{tabular}{|c|c|c|c|c|c|c|c|c|c|c|c|c|c|c|}
\hline & \multicolumn{12}{|c|}{ Time } & \multirow[b]{3}{*}{ Pooled SEM } & \multirow[b]{3}{*}{ Time effect: $P$} \\
\hline & \multicolumn{3}{|c|}{08.30 hours } & \multicolumn{3}{|c|}{09.30 hours } & \multicolumn{3}{|c|}{10.30 hours } & \multicolumn{3}{|c|}{11.30 hours } & & \\
\hline & MS & SRS & $\mathrm{RS}$ & MS & SRS & $\mathrm{RS}$ & MS & SRS & RS & MS & SRS & $\mathrm{RS}$ & & \\
\hline \multicolumn{15}{|c|}{ Nutritionally indispensable amino acids } \\
\hline Arginine & 0.087 & 0.089 & 0.083 & $0.128^{\mathrm{b}}$ & $0 \cdot 179^{\mathrm{a}}$ & $0.094^{\mathrm{b}}$ & $0 \cdot 107^{b}$ & $0 \cdot 163^{\mathrm{a}}$ & $0.084^{c}$ & 0.068 & 0.070 & 0.064 & 0.004 & $<0.001$ \\
\hline Cystine & $0.045^{\mathrm{a}, \mathrm{b}}$ & $0.055^{\mathrm{a}}$ & $0.038^{\mathrm{b}}$ & $0.064^{b}$ & $0.086^{\mathrm{a}}$ & $0.068^{b}$ & 0.045 & 0.059 & 0.046 & 0.034 & 0.037 & 0.034 & 0.001 & $<0.001$ \\
\hline Histidine & 0.036 & 0.038 & 0.032 & $0.041^{b}$ & $0.062^{\mathrm{a}}$ & $0.045^{\mathrm{b}}$ & 0.032 & 0.038 & 0.044 & 0.028 & 0.032 & 0.040 & 0.001 & 0.018 \\
\hline Isoleucine & 0.047 & 0.050 & 0.048 & $0.055^{\mathrm{b}}$ & $0.090^{\mathrm{a}}$ & $0.060^{\mathrm{b}}$ & $0.050^{\mathrm{a}, \mathrm{b}}$ & $0.061^{\mathrm{a}}$ & $0.048^{b}$ & $0.034^{\mathrm{b}}$ & $0.049^{\mathrm{a}}$ & $0.038^{\mathrm{a}, \mathrm{b}}$ & 0.001 & 0.001 \\
\hline Leucine & $0.215^{\mathrm{a}}$ & $0.205^{a}$ & $0.173^{\mathrm{b}}$ & $0.260^{\mathrm{b}}$ & $0.310^{\mathrm{a}}$ & $0 \cdot 245^{\mathrm{b}}$ & $0.254^{\mathrm{a}, \mathrm{b}}$ & $0.271^{\mathrm{a}}$ & $0.204^{\mathrm{b}}$ & 0.154 & 0.148 & 0.142 & 0.004 & $<0.001$ \\
\hline Lysine & $0 \cdot 261^{a, b}$ & $0.287^{\mathrm{a}}$ & $0.233^{b}$ & $0.574^{\mathrm{a}}$ & $0.583^{\mathrm{a}}$ & $0.297^{b}$ & $0.233^{b}$ & $0.320^{\mathrm{a}}$ & $0.227^{b}$ & $0.220^{\mathrm{a}}$ & $0.242^{\mathrm{a}}$ & $0.158^{b}$ & 0.009 & 0.004 \\
\hline Methionine & 0.031 & 0.037 & 0.031 & $0.038^{b}$ & $0.055^{\mathrm{a}}$ & $0.033^{b}$ & $0.034^{\mathrm{b}}$ & $0.061^{a}$ & $0.036^{b}$ & $0.029^{b}$ & $0.040^{\mathrm{a}}$ & $0.028^{b}$ & 0.002 & 0.004 \\
\hline Phenylalanine & 0.089 & 0.085 & 0.083 & $0 \cdot 116^{\mathrm{b}}$ & $0 \cdot 137^{\mathrm{a}}$ & $0 \cdot 102^{b}$ & $0 \cdot 100^{\mathrm{b}}$ & $0.120^{\mathrm{a}}$ & $0 \cdot 103^{b}$ & 0.071 & 0.082 & 0.074 & 0.002 & 0.001 \\
\hline Threonine & $0.380^{\mathrm{b}}$ & $0.452^{\mathrm{a}}$ & $0.375^{\mathrm{b}}$ & $0.422^{c}$ & $0.525^{\mathrm{a}}$ & $0.460^{\mathrm{b}}$ & $0.342^{a, b}$ & $0.384^{\mathrm{a}}$ & $0.308^{b}$ & $0.294^{\mathrm{a}}$ & $0.285^{a}$ & $0.247^{b}$ & 0.010 & $<0.001$ \\
\hline Tryptophan & $0 \cdot 197^{b}$ & $0.235^{a}$ & $0.183^{b}$ & $0.237^{b}$ & $0.288^{a}$ & $0.223^{b}$ & $0.213^{\mathrm{b}}$ & $0.246^{\mathrm{a}}$ & $0.200^{b}$ & $0.166^{b}$ & $0.200^{\mathrm{a}}$ & $0.143^{b}$ & 0.007 & 0.009 \\
\hline Tyrosine & $0.093^{a, b}$ & $0 \cdot 104^{\mathrm{a}}$ & $0.084^{b}$ & $0.118^{b}$ & $0 \cdot 164^{\mathrm{a}}$ & $0 \cdot 117^{b}$ & $0.114^{\mathrm{b}}$ & $0.152^{\mathrm{a}}$ & $0.093^{b}$ & $0.076^{a, b}$ & $0 \cdot 101^{\mathrm{a}}$ & $0.068^{b}$ & 0.002 & $<0.001$ \\
\hline Valine & 0.094 & 0.112 & $0 \cdot 100$ & $0.098^{c}$ & $0 \cdot 166^{\mathrm{a}}$ & $0.129^{b}$ & $0 \cdot 101^{b}$ & $0.138^{\mathrm{a}}$ & $0 \cdot 100^{\mathrm{b}}$ & $0.074^{\mathrm{b}}$ & $0.121^{a}$ & $0.087^{b}$ & 0.002 & 0.011 \\
\hline \multicolumn{15}{|c|}{ Nutritionally dispensable amino acids } \\
\hline Alanine & $0.334^{\mathrm{b}}$ & $0.387^{\mathrm{a}}$ & $0.350^{\mathrm{a}, \mathrm{b}}$ & $0.389^{b}$ & $0.450^{\mathrm{a}}$ & $0.384^{\mathrm{b}}$ & $0.465^{\mathrm{a}, \mathrm{b}}$ & $0.476^{\mathrm{a}}$ & $0.414^{\mathrm{b}}$ & $0.390^{\mathrm{a}}$ & $0.406^{\mathrm{a}}$ & $0.366^{\mathrm{b}}$ & 0.011 & 0.001 \\
\hline Aspartate & 0.022 & 0.025 & 0.028 & 0.032 & 0.030 & 0.030 & 0.042 & 0.049 & 0.042 & $0.026^{b}$ & $0.034^{\mathrm{a}}$ & $0.022^{b}$ & 0.001 & 0.001 \\
\hline Glutamate & 0.227 & 0.241 & 0.226 & $0.278^{a, b}$ & $0.248^{b}$ & $0.298^{\mathrm{a}}$ & $0.318^{\mathrm{a}, \mathrm{b}}$ & $0.324^{\mathrm{a}}$ & $0.279^{b}$ & $0.205^{c}$ & $0.310^{\mathrm{a}}$ & $0.260^{\mathrm{b}}$ & 0.007 & 0.010 \\
\hline Glycine & $0.432^{a, b}$ & $0.463^{\mathrm{a}}$ & $0.410^{\mathrm{b}}$ & $0.520^{a, b}$ & $0.541^{\mathrm{a}}$ & $0.487^{b}$ & $0.545^{\mathrm{a}, \mathrm{b}}$ & $0.549^{\mathrm{a}}$ & $0.522^{b}$ & $0.473^{\mathrm{a}}$ & $0.471^{\mathrm{a}}$ & $0.427^{b}$ & 0.015 & 0.014 \\
\hline Proline & $0.359^{a}$ & $0.337^{a}$ & $0.256^{\mathrm{b}}$ & $0.577^{b}$ & $0.623^{a}$ & $0.555^{\mathrm{b}}$ & $0.492^{b}$ & $0.541^{\mathrm{a}}$ & $0.435^{\mathrm{c}}$ & 0.232 & 0.205 & 0.233 & 0.012 & $<0.001$ \\
\hline Serine & $0.095^{\mathrm{a}, \mathrm{b}}$ & $0 \cdot 105^{\mathrm{a}}$ & $0.084^{\mathrm{b}}$ & 0.124 & 0.117 & 0.122 & $0.095^{\mathrm{a}}$ & $0.089^{a, b}$ & $0.080^{\mathrm{b}}$ & 0.084 & 0.088 & 0.071 & 0.001 & $<0.001$ \\
\hline
\end{tabular}

Mean values within a row, within the same sampling time, with unlike superscript letters were significantly different $(P<0.05)$. 
Table 7. Serum amino acid concentrations after second feeding (mmol/l, continued from Table 6 ) ( $n 6$ per group) (Mean values and pooled standard errors of the mean)

\begin{tabular}{|c|c|c|c|c|c|c|c|c|c|c|c|c|c|c|}
\hline & \multicolumn{12}{|c|}{ Time } & \multirow[b]{3}{*}{ Pooled SEM } & \multirow[b]{3}{*}{ Time effect: $P$} \\
\hline & \multicolumn{3}{|c|}{12.30 hours } & \multicolumn{3}{|c|}{13.30 hours } & \multicolumn{3}{|c|}{14.30 hours } & \multicolumn{3}{|c|}{15.30 hours } & & \\
\hline & MS & SRS & RS & MS & SRS & $\mathrm{RS}$ & MS & SRS & RS & MS & SRS & $\mathrm{RS}$ & & \\
\hline \multicolumn{15}{|c|}{ Nutritionally indispensable amino acids } \\
\hline Arginine & $0.079^{b}$ & $0.112^{\mathrm{a}}$ & $0 \cdot 100^{\mathrm{a}, \mathrm{b}}$ & $0.132^{b}$ & $0.181^{a}$ & $0 \cdot 128^{b}$ & $0.115^{\mathrm{a}, \mathrm{b}}$ & $0.141^{\mathrm{a}}$ & $0.080^{\mathrm{b}}$ & 0.065 & 0.074 & 0.069 & 0.004 & $<0.001$ \\
\hline Cystine & $0.029^{b}$ & $0.036^{\mathrm{a}}$ & $0.036^{\mathrm{a}}$ & $0.043^{\mathrm{b}}$ & $0.056^{\mathrm{a}}$ & $0.041^{\mathrm{b}}$ & 0.034 & 0.037 & 0.034 & 0.033 & 0.034 & 0.030 & 0.001 & $<0.001$ \\
\hline Histidine & 0.043 & 0.051 & 0.046 & $0.041^{\mathrm{b}}$ & $0.063^{\mathrm{a}}$ & $0.049^{b}$ & 0.042 & 0.041 & 0.050 & 0.031 & 0.037 & 0.040 & 0.001 & 0.018 \\
\hline Isoleucine & $0.037^{b}$ & $0.057^{\mathrm{a}}$ & $0.056^{\mathrm{a}}$ & $0.055^{\mathrm{b}}$ & $0.090^{\mathrm{a}}$ & $0.060^{\mathrm{b}}$ & 0.056 & 0.066 & 0.047 & $0.036^{\mathrm{b}}$ & $0.049^{\mathrm{a}}$ & $0.041^{a, b}$ & 0.001 & 0.001 \\
\hline Leucine & 0.184 & 0.192 & 0.177 & $0.278^{\mathrm{a}}$ & $0.271^{\mathrm{a}}$ & $0.204^{\mathrm{b}}$ & $0.254^{\mathrm{a}}$ & $0.213^{\mathrm{b}}$ & $0.208^{b}$ & 0.179 & 0.159 & 0.167 & 0.004 & $<0.001$ \\
\hline Lysine & $0.272^{b}$ & $0.302^{\mathrm{a}}$ & $0.234^{\mathrm{b}}$ & $0.574^{\mathrm{a}}$ & $0.583^{a}$ & $0.297^{b}$ & $0.497^{\mathrm{a}}$ & $0.491^{a}$ & $0.222^{b}$ & 0.263 & 0.276 & 0.269 & 0.009 & 0.004 \\
\hline Methionine & $0.032^{b}$ & $0.044^{\mathrm{a}}$ & $0.034^{b}$ & $0.038^{b}$ & $0.055^{a}$ & $0.033^{b}$ & $0.037^{a, b}$ & $0.046^{\mathrm{a}}$ & $0.032^{b}$ & $0.030^{\mathrm{b}}$ & $0.039^{\mathrm{a}}$ & $0.030^{\mathrm{b}}$ & 0.002 & 0.004 \\
\hline Phenylalanine & 0.087 & 0.096 & 0.096 & $0.100^{\mathrm{b}}$ & $0.133^{\mathrm{a}}$ & $0 \cdot 103^{b}$ & $0 \cdot 100^{\mathrm{a}, \mathrm{b}}$ & $0.105^{\mathrm{a}}$ & $0.088^{b}$ & 0.077 & 0.087 & 0.082 & 0.002 & 0.001 \\
\hline Threonine & $0.316^{\mathrm{b}}$ & $0.392^{\mathrm{a}}$ & $0.345^{a, b}$ & $0.380^{\mathrm{b}}$ & $0.452^{\mathrm{a}}$ & $0.375^{\mathrm{b}}$ & $0.411^{\mathrm{a}}$ & $0.374^{\mathrm{a}}$ & $0.126^{\mathrm{b}}$ & $0.326^{\mathrm{a}}$ & $0.276^{a, b}$ & $0.257^{b}$ & 0.010 & $<0.001$ \\
\hline Tryptophan & $0 \cdot 192^{b}$ & $0.243^{\mathrm{a}}$ & $0 \cdot 171^{b}$ & $0.226^{b}$ & $0.280^{\mathrm{a}}$ & $0.223^{b}$ & $0.217^{b}$ & $0.252^{\mathrm{a}}$ & $0.208^{b}$ & $0.156^{b}$ & $0.190^{\mathrm{a}}$ & $0.147^{b}$ & 0.007 & 0.009 \\
\hline Tyrosine & $0.090^{\mathrm{b}}$ & $0.128^{\mathrm{a}}$ & $0.094^{\mathrm{b}}$ & $0.114^{\mathrm{b}}$ & $0.164^{\mathrm{a}}$ & $0.093^{b}$ & $0.116^{a, b}$ & $0.146^{\mathrm{a}}$ & $0.092^{b}$ & $0.083^{a, b}$ & $0.112^{\mathrm{a}}$ & $0.074^{\mathrm{b}}$ & 0.002 & $<0.001$ \\
\hline Valine & $0.082^{b}$ & $0.127^{\mathrm{a}}$ & $0 \cdot 117^{\mathrm{a}}$ & $0.098^{\mathrm{c}}$ & $0.166^{\mathrm{a}}$ & $0.129^{b}$ & $0.100^{\mathrm{b}}$ & $0.138^{\mathrm{a}}$ & $0 \cdot 101^{\mathrm{b}}$ & $0.074^{\mathrm{b}}$ & $0.120^{\mathrm{a}}$ & $0.089^{a, b}$ & 0.002 & 0.011 \\
\hline \multicolumn{15}{|c|}{ Nutritionally dispensable amino acids } \\
\hline Alanine & $0.434^{\mathrm{b}}$ & $0.473^{\mathrm{a}}$ & $0.452^{\mathrm{a}, \mathrm{b}}$ & $0.474^{\mathrm{b}}$ & $0.480^{\mathrm{b}}$ & $0.569^{\mathrm{a}}$ & $0.594^{\mathrm{a}}$ & $0.582^{\mathrm{a}}$ & $0.486^{b}$ & $0.341^{\mathrm{b}}$ & $0.530^{\mathrm{a}}$ & $0.374^{\mathrm{b}}$ & 0.011 & 0.001 \\
\hline Aspartate & 0.029 & 0.033 & 0.036 & 0.033 & 0.035 & 0.044 & 0.042 & 0.033 & 0.041 & 0.027 & 0.036 & 0.029 & 0.001 & 0.001 \\
\hline Glutamate & $0.226^{b}$ & $0.273^{\mathrm{a}}$ & $0.282^{\mathrm{a}}$ & 0.266 & 0.291 & 0.299 & 0.319 & 0.305 & 0.345 & $0.227^{b}$ & $0.319^{\mathrm{a}}$ & $0.252^{a, b}$ & 0.007 & 0.010 \\
\hline Glycine & $0.525^{\mathrm{a}}$ & $0.491^{\mathrm{a}, \mathrm{b}}$ & $0.479^{b}$ & $0.624^{\mathrm{a}}$ & $0.551^{\mathrm{b}}$ & $0.590^{\mathrm{a}, \mathrm{b}}$ & $0.684^{\mathrm{a}}$ & $0.587^{b}$ & $0.483^{\mathrm{c}}$ & $0.473^{\mathrm{a}, \mathrm{b}}$ & $0.499^{\mathrm{a}}$ & $0.444^{\mathrm{b}}$ & 0.015 & 0.014 \\
\hline Proline & $0.527^{b}$ & $0.561^{\mathrm{a}}$ & $0.537^{\mathrm{b}}$ & $0.781^{\mathrm{a}}$ & $0.727^{\mathrm{a}}$ & $0.512^{\mathrm{b}}$ & $0.714^{\mathrm{a}}$ & $0.654^{\mathrm{b}}$ & $0.330^{\mathrm{c}}$ & $0.269^{\mathrm{a}}$ & $0.252^{\mathrm{a}}$ & $0 \cdot 218^{\mathrm{b}}$ & 0.012 & $<0.001$ \\
\hline Serine & $0 \cdot 101$ & $0 \cdot 100$ & 0.089 & $0.115^{\mathrm{a}, \mathrm{b}}$ & $0.126^{a}$ & $0.093^{b}$ & $0.115^{\mathrm{a}}$ & $0.108^{a, b}$ & $0.084^{\mathrm{b}}$ & 0.088 & 0.089 & 0.077 & 0.001 & $<0.001$ \\
\hline
\end{tabular}

MS, maize starch; SRS, sticky rice starch, RS, resistant starch.

${ }_{a, b, c}$ Mean values within a row, within the same sampling time, with unlike superscript letters were significantly different $(P<0.05)$ 


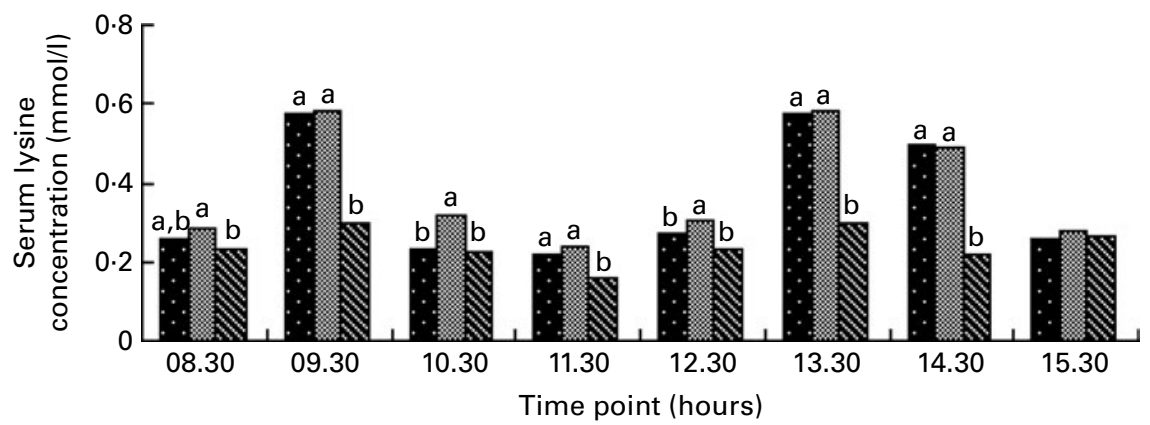

Fig. 1. Variation in postprandial serum systemic circulating lysine in two feeding cycles. (国), Maize starch-fed group; (图), sticky rice starch-fed group; ( $\mathbf{s}$ ), resistant starch-fed group. Values are means ( $n 6$ per group). ${ }^{\mathrm{a}, \mathrm{b}}$ Mean values, within the same sampling time, with unlike letters were significantly different $(P<0 \cdot 05)$.

starch and RS have different effects on postprandial blood glucose and insulin levels.

The small intestine is an important organ that is responsible for the digestion of dietary starch and protein, as well as the absorption of free glucose, small peptides and free $\mathrm{AA}^{(23,24)}$. Different fractions of nutritional ingredients in the small intestine would improve or inhibit each other's absorption into enterocytes. In the present study, amylopectin was digested rapidly but amylose was digested slowly and increased the viscosity of digesta ${ }^{(25)}$. Increasing the viscosity of digesta could inhibit the nutritional ingredients making contact with digestive enzymes, thus decreasing the digestibility of nutritional ingredients ${ }^{(26-28)}$, such as protein and
AA. Such digestion-resistant effects may be enhanced as the dietary concentration of amylose increases ${ }^{(29)}$. This is one of the reasons why the in vivo digestibility of SRS is greater in the anterior jejunum (Table 5) and the apparent posterior ileum digestibility of AA in the SRS group is higher than in the MS and RS groups. Increased digestibility of protein would result in increased absorption of free AA into enterocytes. Although branched-chain AA, aspartate, glutamate, glutamine, proline and arginine are extensively catabolised by enterocytes of post-weaning pigs ${ }^{(30,31)}$, degradation of other AA is absent or negligible in these cells ${ }^{(32)}$. Thus, serum concentrations of nutritionally indispensable AA in the SRS group were remarkably higher at 09.30 and 13.30

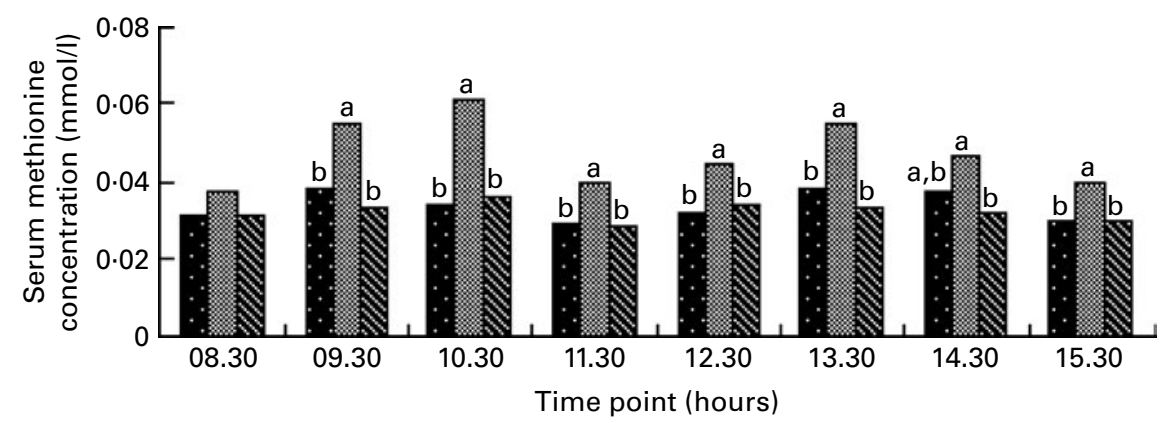

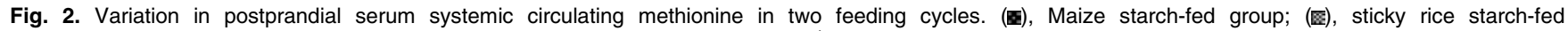
group; (\$\$), resistant starch-fed group. Values are means ( $n 6$ per group). ${ }^{a, b}$ Mean values, within the same sampling time, with unlike letters were significantly different $(P<0.05)$.

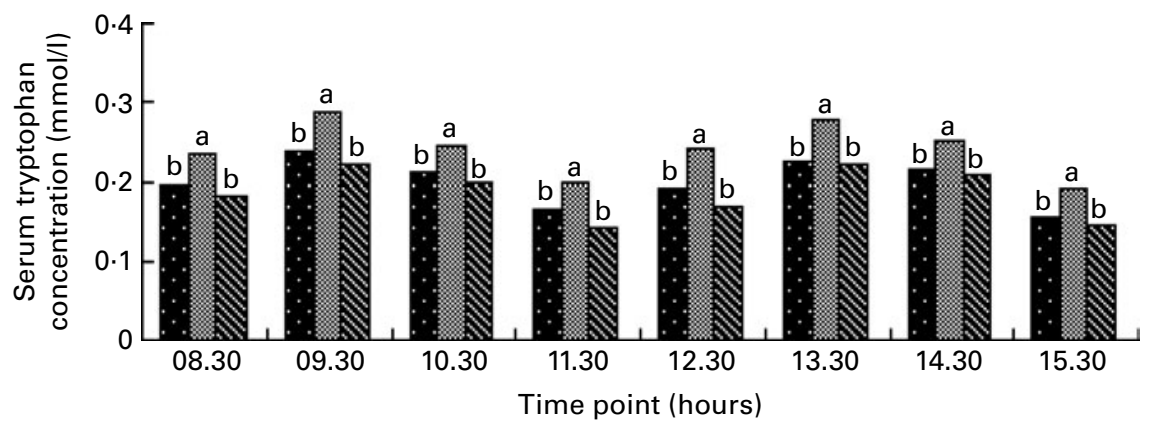

Fig. 3. Variation in postprandial serum systemic circulating tryptophan in two feeding cycles. (医), Maize starch-fed group; (医), sticky rice starch-fed group; (\$心), resistant starch-fed group. Values are means ( $n 6$ per group). ${ }^{a, b}$ Mean values, within the same sampling time, with unlike letters were significantly different $(P<0.05)$. 
hours (Tables 5 and 6). Because muscle protein synthesis is very sensitive to the circulating levels of AA in young pigs ${ }^{(33,34)}$ via mammalian target of rapamycin (mTOR) and perhaps other signalling pathways ${ }^{(35,36)}$, the higher levels of serum concentrations of AA would promote protein accretion and thus growth performance in early-weaned pigs.

We have observed that postprandial serum glucose concentration in the SRS group was higher and could be sustained for $3.5 \mathrm{~h}$ after the pigs consumed their meals ${ }^{(37)}$. Glucose is an important signal molecule in regulating the AA transporters and stimulating protein synthesis through an mTOR pathway ${ }^{(38-40)}$. Higher levels of serum glucose amend the phosphorylation level of mTOR thus increasing the amount of AA absorbed into the systemic circulation to meet the needs of protein synthesis. This is the second reason for the higher digestibility of AA and serum AA levels in the SRS group.

In summary, although the precise mechanisms responsible for affecting postprandial serum AA levels of dietary starches with different digestion rates remains to be explored, it was indicated from our present study that dietary starches digested rapidly in vitro would positively reflect higher digestibility of those starches in the anterior small intestine of pigs. A diet containing higher levels of rapidly digestible starch ameliorates the digestive and absorptive function and keeps the systemic circulating concentrations of most AA higher within $4 \mathrm{~h}$ postprandially in pigs.

\section{Acknowledgements}

This research was supported by grants from the National Natural Science Foundation of China (NSFC; no. 30671517). The authors are grateful to all other staff in the Laboratory of Animal Nutritional Physiology and Metabolic Process, Institute of Subtropical Agriculture, the Chinese Academy of Sciences for their assistances in the present study.

Y. Y. was in charge of the whole trial. F. Y. conducted the in vitro digestibility trial, animal experiment and wrote the whole of the paper. Z. Z. and J. H. assisted with the animal trial and chemical analyses.

The authors have no conflicts of interest.

\section{References}

1. Knudsen KEB, Lærke HN, Steenfeldt S, et al. (2006) In vivo methods to study the digestion of starch in pigs and poultry. Anim Feed Sci Technol 130, 114-135.

2. Wiseman J (2006) Variations in starch digestibility in nonruminants. Anim Feed Sci Technol 130, 66-77.

3. Englyst HN, Kingman SM \& Cummings JH (1992) Classification and measurement of nutritionally important starch fractions. Eur J Clin Nutr 46, S33-S50.

4. Englyst HN \& Hudson GJ (1996) The classification and measurement of dietary carbohydrates. Food Chem 57, 15-21.

5. Englyst KN, Englyst HN, Hudson GJ, et al. (1999) Rapidly available glucose in foods: an in vitro measurement that reflects the glycemic response. Am J Clin Nutr 69, 448-454.

6. Van der Meulen BYJ, Bakker JGM, Smits B, et al. (1997) Effect of source of starch on net portal flux of glucose, lactate, volatile fatty acids and amino acids in the pig. Br J Nutr $\mathbf{7 8}$, 533-544.
7. Noah L, Krempf M, Lecannu G, et al. (2000) Bioavailability of starch and postprandial changes in splanchnic glucose metabolism in pigs. Am J Physiol Endocrinol Metab 278, E181-E188.

8. Liu JG, Zhang P, Bin SY, et al. (2007) Effects of different dietary starch constituents on level of blood glucose and insulin of weaned piglets (article in Chinese). Food Sci 28 , $315-319$

9. Hung PV \& Morita N (2005) Physicochemical properties and enzymatic digestibility of starch from edible canna (Canna edulis) grown in Vietnam. Carbohydr Polym 61, 314-321.

10. Huang RL, Yin YL, Wang KP, et al. (2003) Nutritional value of fermented and not fermented material of distiller's grains in pig nutrition. J Anim Food Sci 12, 261-269.

11. Li TJ, Dai QZ, Yin YL, et al. (2008) Dietary starch sources affect net portal appearance of amino acids and glucose in growing pigs. Animal 2, 723-729.

12. National Research Council (1998) Nutrient Requirements of Swine. Washington, DC: National Academy Press.

13. AOAC (2003) Official Methods of Analysis, 17th ed. Arlington, VA: AOAC International.

14. American Association of Cereal Chemists (2000) Approved Methods of the AACC, 10th ed. St Paul, MN: AACC.

15. Yao K, Yin YL, Chu WY, et al. (2008) Dietary arginine supplementation increases mTOR signaling activity in skeletal muscle of neonatal pigs. $J$ Nutr 138, 867-872.

16. Yin FG, Liu YL, Yin YL, et al. (2009) Dietary supplementation with Astragalus polysaccharide enhances ileal digestibilities and serum concentrations of amino acids in early weaned piglets. Amino Acids 37, 263-270.

17. Yin YL, McEvoy J, Schulze H, et al. (2000) Studies on cannulation method and alternative indigestible markers and the effects of food enzyme supplementation in barley-based diets on ileal and overall apparent digestibility in growing pigs. Anim Sci 70, 63-72.

18. Fan MZ, Li TJ, Yin YL, et al. (2005) Effect of phytase supplementation with two levels of phosphorus diets on ileal and faecal digestibilities of nutrients and phosphorus, calcium, nitrogen and energy balances in growing pigs. Anim Sci 81, 67-75.

19. Englyst HN, Veenstra J \& Hudson GJ (1996) Measurement of rapidly available glucose (RAG) in plant foods: a potential in vitro predictor of the glycaemic response. $\mathrm{Br} J$ Nutr $\mathbf{7 5}$, 327-337.

20. Cummings JH, Beatty ER, Kingman SM, et al. (1996) Digestion and physiological properties of resistant starch in the human large bowel. Br J Nutr 75, 733-747.

21. Ells LJ, Seal CJ, Kettlitz B, et al. (2005) Postprandial glycaemic, lipaemic and haemostatic responses to ingestion of rapidly and slowly digested starches in healthy young women. Br J Nutr 94, 948-955.

22. Lehmann U \& Robin F (2007) Slowly digestible starch - its structure and health implications: a review. Trends Food Sci Technol 18, 346-355.

23. Gary MG (1992) Starch digestion and absorption in nonruminants. J Nutr 22, 172-177.

24. Libao-Mercado AJ, Yin Y, van Eys J, et al. (2006) True ileal amino acid digestibility and endogenous ileal amino acid losses in growing pigs fed wheat shorts- or casein-based diets. J Anim Sci 84, 1351-1361.

25. Sasaki T, Yasui T \& Matsuki J (2000) Effect of amylose content on gelatinization, retrogradation, and pasting properties of starches from waxy and nonwaxy wheat and their F1 seeds. Cereal Chem 77, 58-63.

26. Siddhuraju P \& Becker K (2005) Nutritional and antinutritional composition, in vitro amino acid availability, starch digestibility and predicted glycemic index of differentially processed 
mucuna beans (Mucuna pruriens var. utilis): an under-utilised legume. Food Chem 91, 275-286.

27. Siddhuraju P, Becker K \& Makkar HPS (2000) Studies on the nutritional composition and antinutritional factors of three different germplasm seed materials of an under-utilized tropical legume, Mucuna pruriens Var. Utilis. Agric Food Chem 48, 6048-6060.

28. Owens FN, Zinn RA \& Kim YK (1986) Limits to starch digestion in the ruminant small intestine. J Anim Sci 63, $1634-1648$.

29. Åkerberg A, Liljeberg H \& Björck I (1998) Effects of amylose/ amylopectin ratio and baking conditions on resistant starch formation and glycaemic indices. J Cereal Sci 28, 71-80.

30. Wu GY, Knabe DA \& Flynn NE (1994) Synthesis of citrulline from glutamine in pig enterocytes. Biochem $J \mathbf{2 9 9}$, $115-121$

31. Wu GY (1997) Synthesis of citrulline and arginine from proline in enterocytes of postnatal pigs. Am J Physiol Gastrointest Liver Physiol 272, G1382-G1390.

32. Chen LX, Yin YL, Jobgen WS, et al. (2007) In vitro oxidation of essential amino acids by intestinal mucosal cells of growing pigs. Livest Sci 109, 19-23.

33. Davis TA, Burrin DG, Fiorotto ML, et al. (1998) Role of insulin and amino acids in the regulation of protein synthesis in the neonate. J Nutr 128, 347S-350S.
34. Frank JW, Escobar J, Hguyen HV, et al. (2007) Oral N-carbamylglutamate supplementation increases protein synthesis in skeletal muscle of piglets. $J$ Nutr 137, 315-319.

35. Davis TA, Nguyen HV, Suryawan A, et al. (2000) Developmental changes in the feeding-induced stimulation of translation initiation in muscle of neonatal pigs. Am J Physiol Endocrinol Metab 279, E1226-E1234.

36. Jobgen WS, Fried SK, Fu WJ, et al. (2006) Regulatory role for the arginine-nitric oxide pathway in metabolism of energy substrates. J Nutr Biochem 17, 571-588.

37. Yin F, Huang J, Zhang Z, et al. (2009) Determination of digestion rates of dietary starches by in vivo and in vitro method and their effects on physiologic status of weanling pig. Livest Sci (In the Press).

38. Roos S, Lagerlöf O, Wennergren M, et al. (2009) Regulation of amino acid transporters by glucose and growth factors in cultured primary human trophoblast cells is mediated by mTOR signaling. Am J Physiol Cell Physiol 297, C723-C731.

39. Kwon G, Marshall CA, Liu H, et al. (2006) Glucose-stimulated DNA synthesis through mammalian target of rapamycin (mTOR) is regulated by $\mathrm{K}_{\mathrm{ATP}}$ channels. J Biol Chem 281, 3261-3267.

40. Gleason CE, Lu D, Witters LA, et al. (2007) The role of AMPK and mTOR in nutrient sensing in pancreatic $\beta$-cells. $J$ Biol Chem 282, 10341-10351. 